\title{
An Integrated Multi-criteria Structural Equation Model for Green Supplier Selection
}

\author{
Rahmi Baki ${ }^{1}[$
}

Received: 9 August 2021 / Revised: 30 November 2021 / Accepted: 13 December 2021 / Published online: 10 January 2022

(c) Korean Society for Precision Engineering 2022

\begin{abstract}
The aims of the current study are to determine the criteria to be considered in a green supplier selection (GSS) process, develop an integrated decision-making approach using structural equation modelling (SEM) and fuzzy additive ratio assessment (ARAS) techniques to rank suitable suppliers, and investigate the effectiveness of this approach in collective decisionmaking. The study's ultimate objective is to propose a method created from the perspective of fuzzy logic in which criterion weights are determined using SEM to resolve decision-making challenges such as GSS, in which a compromise solution is desired. In the first stage of the study, relevant literature as examined in detail. Eight main criteria and 27 sub-criteria were detected, taking into account classical, green, and social supplier selection (SS) criteria. A questionnaire was administered to 254 participants who were actively involved in SS processes for their companies, and the data were analyzed using SEM. In the second phase, six suppliers were evaluated considering the criteria found to have a positive impact on GSS, and fuzzy ARAS was applied. The results showed that the factors affecting GSS are quality (0.291), social responsibility $(0.222)$, service $(0.21)$, cost (0.149) and green product (0.128). The study presents an effective, objective, and fast method that can be used in decision-making problems such as GSS, that prevents potential loss of information and lack of transparency through an integrated approach, and that can be tested with a generalizable framework. The proposed hybrid method is an efficient and practical approach that can be tested on many decision-making problems, such as SS.
\end{abstract}

Keywords Green supplier selection · Fuzzy logic $\cdot$ Structural equation modeling $\cdot$ Additive ratio assessment

\section{Introduction}

To gain a competitive advantage in today's business environment, firms must work in close cooperation with external partners. For this reason, they must focus on the identification and selection of supply sources. Supplier selection (SS) has a significant impact on the competitiveness of the entire supply chain (SC) network [1]. SS is an essential component of strategic processes-making the wrong decision can have crucial direct and indirect consequences.

The rapid depletion of natural resources, increased environmental awareness of consumers, and sanctions from governments have obliged companies to improve their green performance. Environmental sensitivities on the part of manufacturers and suppliers have become the focus of

Rahmi Baki

rahmi.baki@hotmail.com

1 Department of Management Information Systems, Aksaray University, Bahçesaray District, 68100 Aksaray, Turkey much more discussion and research [17]. This emphasis also affects firms' SS decisions to include the concept of green supplier selection (GSS). Taking green criteria into account has become increasingly important [4]. Therefore, both economic and green factors, as well as social variables, should be included in the evaluation of suppliers to ensure sustainable development. However, choosing the appropriate green supplier is more difficult than traditional SS, as it requires consideration of conflicting environmental criteria [10]. GSS requires multi-criteria decision making (MCDM) and is one of the most critical processes in SC management due to its long-term implications [34].

In the many studies on efficient GSS using MCDM techniques, the selection process generally took place in two stages. In the first stage, weighting the criteria that affect GSS was addressed, and in the second stage, supplier alternatives were ranked. Different techniques are integrated into the two processes, and fuzzy logic is usually included in the proposed approach. In the first stage of the current study, assigning weights to the factors affecting GSS was 
performed using structural equation modeling (SEM), while in the second phase, suppliers were ranked by the fuzzy additive ratio assessment (ARAS).

First, the studies on GSS in the literature and the criteria used in these studies were examined in a systematic and detailed way. At the end of this process, eight main criteria and 27 sub-criteria had been detected. While determining the criteria, care was taken to consider classical, environmental, and social SS criteria. Then, whether the determined criteria had a positive and significant effect on SS was tested using SEM, an effective method for testing and estimating the causality relationship with no limitation on the number of variables [51]. The supplier alternatives of a company operating in the textile sector were evaluated by considering the criteria that have positive effects on GSS. The ARAS technique is an effective MCDM technique that ranks decision alternatives according to utility function value, taking into account various criteria. In addition, the fuzzy ARAS technique was used to overcome the uncertainty and complexity that may be encountered in real life situations.

GSS has become a strategic way to gain a competitive advantage in today's business environment. Evaluating and selecting a potential green supplier is a complex decisionmaking task involving significant uncertainties. The method developed in this research from the perspective of fuzzy logic takes criterion weights into account using SEM to help assess the criteria.

The proposed integrated method provides both theoretical and practical benefits to researchers and managers. The complexity of evaluation information is a common phenomenon in practical decision-making, and SEM is a powerful tool for dealing with uncertainties. In this study, the problem was overcome by using an approach created within the scope of SEM to evaluate criteria in the decision-making process. In addition, the proposed decision-making model allows information to be handled in an appropriate and flexible way in areas in which a compromise solution is accepted and allows decision makers to express their judgment about the criteria in an objective way. This study presents an approach in which strategic decisions can be taken effectively and impartially, especially in such challenges as GSS when conflicts of opinion can be intense. The methodology used in criterion weighting is a fast and effective tool that does not require implementing pairwise comparisons. The scalable, efficient, generalizable, and practical approach proposed, which uses SEM and fuzzy ARAS methods together, prevents the potential loss of critical information and ensures transparency. Applying SEM and fuzzy logic together has not been tested in previous literature. This integrated approach seems to be a new and expandable methodology that can be used in various decision-making problems, especially in GSS.

The remaining structure of this study is organized as follows. Chapter 2 reviews studies aiming effectively at GSS using MCDM methods and their results. In Chapter 3, the hypotheses and criteria proposed in this study are introduced. In Chapter 4, the proposed method for criterion weighting and ranking of supplier alternatives is introduced, and an explanatory example is given relating to the SS of a company in the textile industry. Finally, findings and recommendations for future research are presented in Chapter 5 .

\section{Literature Review}

Today, as a result of intense competition among companies and customers' changing expectations, significant changes have occurred in SS practices. In this environment, it is increasingly difficult to identify suitable suppliers-a critical decision for firms. As a result of increasing environmental concerns, legal obligations, and changing customer demands, companies have changed their SS strategies, and as a result, they focus on GSS. Many studies have been conducted using a range of methods for supplier evaluation. Studies aiming at effective GSS using MCDM techniques are included in this part.

Chiou et al. [15] analyzed the differences in GSS in the electronics industry of three countries using the fuzzy AHP technique. Lee et al. [41] used Delphi and AHP techniques to better understand the characteristics of suppliers in the high-tech industry and to contribute to the GSS process. Kuo et al. [40] compared the results of two hybrid approaches for GSS in an international camera company. Amindoust et al. [3] presented an approach for sustainable supplier evaluation and ranking with an approach based on the fuzzy inference system. Büyüközkan [9] proposed a model that considers various environmental performance criteria with an AHP and axiomatic design-based approach. Iirajpour et al. [32] used the DEMATEL technique to determine the effective factors in GSS.

Kannan et al. [35] described a model in which utility theory and multi-objective programming are used together to realize GSS and determine the optimum order quantity, taking into account classical and environmental criteria. Banaeian et al. [6] revealed a model using Delphi and data envelopment analysis to determine the best supplier for edible oil production. Mina et al. [47] presented a two-phase method based on Delphi and fuzzy AHP for GSS in a pharmaceutical company. Beng and Omar [7] developed an axiomatic design-based approach to assist decision making in the areas of end-of-life management, green SC and sustainable production. Orji and Wei [48] developed an approach for efficient sustainable SS using fuzzy logic, DEMATEL, and TOPSIS. The developed approach was tested in a gear manufacturing facility.

Banaeian et al. [5] introduced an operational model for GSS criteria in the food industry, which includes a 
combination of general and environmental criteria using AHP and Delphi techniques. Gurel et al. [26] prepared a hierarchical list of criteria for GSS in the textile industry to integrate multi-criteria decisions. Meng et al. [46] developed a life cycle assessment approach from an environmental perspective using intuitionistic fuzzy theory and Monte Carlo methods. Soubhia et al. (2015) analyzed the relationship between proactive environmental management practices and the environmental performance of companies through SEM. Acar et al. [1] examined the parameters that affect GSS decision making in the textile industry using the fuzzy AHP technique. Although it was determined in the study that environmental criteria were effective in SS, it was observed that classical criteria were still given higher priority. Sharma and Rawani [57] applied the AHP technique for GSS in the cement industry, and $\mathrm{Yu}$ and Hou [65] tested a modified AHP technique for GSS in a motor company.

Bakeshlou et al. [4] improved a five-objective GSS model by using ANP and AHP techniques together. Fallahpour et al. [18] proposed a method to determine the most sustainable supplier for a textile manufacturing company, according to the determined qualifications, using AHP and TOPSIS techniques. Guo et al. [25] introduced an approach for GSS in apparel manufacturing using BWM and TOPSIS techniques. Gupta and Barua [24] aimed to select a suitable supplier for SMEs, from the perspective of green innovation capabilities, using BWM and TOPSIS techniques. Luthra et al. [44] presented a framework in which AHP and VIKOR approaches were used together to provide systematic and sustainable evaluation in the SS of the automobile industry. Tavana et al. [61] presented a new approach for sustainable SS through an integrated approach from the perspective of ANP and quality function deployment in their study. The proposed approach was used in the SS of a dairy business.

Tian et al. [62] used BWM and TOPSIS techniques together to solve the GSS problem in the agriculture sector. Zafar et al. [67] revealed an extended fuzzy AHP approach for the most suitable GSS and tested the proposed approach in the SS of a textile company. Chatterjee and Stević [11] developed a decision-making model as a support tool to optimize the purchasing process and to reinforce cooperation with a potential supplier. Fuzzy AHP and fuzzy TOPSIS methods are used in their proposed two-stage model. Kuo and Wang [39] created a process in which robust design criteria and axiomatic design principles are used together so that designers can develop sustainable products more easily. Liu et al. [42] improved a method for GSS from the perspective of quality function deployment and a partitioned Bonferroni mean. Lu et al. [43] presented a cloud model and a possibility degree-based approach to guide the ranking of the most suitable suppliers. Memari et al. [45] tested the TOPSIS technique for SS in an automotive manufacturer. Phochanikorn and Tan [49] proposed a comprehensive model based on DEMATEL, ANP, and prospect theory to synthesize psychological and behavioral factors in GSS and to rank suitable suppliers according to orders. The proposed model has been tested in the SS of a palm oil producing company. Stević et al. [60] proposed an approach based on fuzzy AHP and fuzzy EDAS methods for the SS of a company producing plastic bags and foil. The obtained results were tested in a sensitivity analysis in which 15 scenarios were created, and the stability of the model was determined. Yucesan et al. [66] applied their proposed approach based on BWM and fuzzy TOPSIS methods on a plastic injection molding company's GSS strategy.

Biswas and Das [8] identified SC problems caused by the COVID-19 pandemic in the manufacturing sector and examined their effects with a method based on the fuzzy AHP technique. The study revealed that a manpower shortage was the greater problem compared to other criteria. Chattopadhyay et al. [12] tested a method based on the D-MARCOS technique to identify the best performing suppliers in the iron and steel industry. Three decision makers evaluated suppliers by considering seven evaluation criteria. Ecer [17] used the fuzzy AHP technique to solve the GSS problem of a home appliance manufacturer. Jain and Singh [33] proposed a model in which fuzzy Kano and fuzzy inference system approaches were used together for sustainable SS in large-scale companies. Javad et al. [34] proposed a model for a firm operating in the steel industry to select suppliers according to green innovation capabilities through BWM and fuzzy TOPSIS techniques. Kannan et al. [36] used BWM and VIKOR techniques for sustainable SS in circular SCs. Ramakrishnan and Chakraborty [52] proposed the cloud TOPSIS model for the solution of GSS problems in the automobile sector. Roy et al. [53] used AHP and PROMETHEE to evaluate sustainable SS methods and tested their proposed approach in a ready-made clothing company.

Alipour et al. [2] presented a model based on Entropy, SWARA, and Pythagorean fuzzy COPRAS techniques to evaluate suppliers of hydrogen. The approach aimed to overcome inadequacies that arise in objective or subjective weighting models. Fazlollahtabar and Kazemitash [19] designed a GSS process from the perspective of conducting performance evaluations of information systems. For this purpose, using BWM, the performance and effectiveness of companies' information systems were analysed from the standpoint of GSS. Wu et al. [63] developed a decisionmaking model in the chemical industry to select sustainable suppliers and respond quickly to market demands. In their study, specific characteristics of the chemical industry were taken into account, and the DEMATEL technique was used. Yazdani et al. [64] presented an SS framework based on different criteria and the interval-valued fuzzy neutrosophic model, which has been tested in the supplier evaluation of a dairy company in Iran. 
In the literature review, it was seen that many MCDM techniques are used in studies aimed at solving GSS problems. In most studies, the selection process is divided into two processes-determining criteria affecting the SS and supplier ranking. Some researchers used two or more techniques together in these two processes and generally integrated fuzzy logic into their proposed approaches.

In the current study, GSS was examined in two processes. However, unlike other studies in the literature, in the first phase, the weights of the criteria affecting GSS were determined using SEM, and in the second phase, suppliers were ranked via fuzzy ARAS. In a few studies in the literature, SEM was used to determine criterion weights. Punniyamoorthy et al. [51], through SEM and a fuzzy AHP technique, proposed a model for solving SS problems using classical SS criteria. Punniyamoorty et al. [50] analyzed the same approach for SS using different criteria. Gbongli et al. [20] used a combination of TOPSIS, AHP, and SEM techniques to understand and prioritize decision alternatives for mobile financial services.

\section{Theoretical Framework and Proposed Hypotheses}

In the present study, articles related to GSS in the literature and the criteria they had taken into account were examined. As a result, eight criteria were determined to test the effects of GSS (Table 1). Criteria used in the studies were cost, quality, delivery, service, technology, social responsibility, environmental competency, and green product. The positive effect on SS of these eight criteria was explored in depth.

Cost is generally the primary evaluation criterion in traditional SS approaches [1]. The theoretical basis for evaluating suppliers began from the resource-based perspective and cost economy of organizations [29]. In studies in which traditional criteria were taken into account, cost or price criteria were emphasized as the main concern of the industries [58]. The concept of cost can be expanded or subdivided into many cost elements, such as purchasing,

Table 1 The criteria for GSS

\begin{tabular}{|c|c|c|}
\hline Criteria & Sub-criteria & References \\
\hline Cost & $\begin{array}{l}\text { Product price } \\
\text { Transportation cost } \\
\text { Quantity discount } \\
\text { Payment terms }\end{array}$ & $\begin{array}{l}\text { Acar et al. [1], Bakeshlou et al. [4], Fallahpour et al. [18], Guo et al. [25], Gurel } \\
\text { et al. [26], Jain and Singh [33], Kannan et al. [35], Kuo et al. [40], Mina et al. } \\
\text { [47], Sharma and Rawani [57], Yucesan et al. [66] }\end{array}$ \\
\hline Quality & $\begin{array}{l}\text { Quality assurance } \\
\text { Quality related certificates } \\
\text { Low defect rate } \\
\text { Low rejection rate }\end{array}$ & $\begin{array}{l}\text { Acar et al. [1], Bakeshlou et al. [4], Fallahpour et al. [18], Guo et al. [25], Gurel } \\
\text { et al. [26], Jain and Singh [33], Kannan et al. [35], Kuo et al. [40], Lee et al. } \\
\text { [41], Mina et al. [47], Ramakrishnan and Chakraborty [52], Sharma and } \\
\text { Rawani [57], Yucesan et al. [66], Zafar et al. [67] }\end{array}$ \\
\hline Delivery & $\begin{array}{l}\text { Order fulfillment rate } \\
\text { On time delivery } \\
\text { Delivery communication system }\end{array}$ & $\begin{array}{l}\text { Acar et al. [1], Banaeian et al. [5], Banaeian et al. [6], Fallahpour et al. [18], } \\
\text { Guo et al. [25], Gurel et al. [26], Jain and Singh [33], Kannan et al. [35], Kuo } \\
\text { et al. [40], Lu et al. [43], Ramakrishnan and Chakraborty [52], Tian et al. } \\
\text { [62] }\end{array}$ \\
\hline Service & $\begin{array}{l}\text { Guarantee } \\
\text { Responsiveness } \\
\text { After sales service }\end{array}$ & $\begin{array}{l}\text { Acar et al. [1], Bakeshlou et al. [4], Büyüközkan [9], Guo et al. [25], Gurel et al. } \\
\text { [26], Jain and Singh [33], Kuo et al. [40], Lee et al. [41], Ramakrishnan and } \\
\text { Chakraborty [52], Sharma and Rawani [57], Yucesan et al. [66], }\end{array}$ \\
\hline Technology & $\begin{array}{l}\text { Technological development } \\
\text { Capability of R and } \mathrm{D} \\
\text { New product design }\end{array}$ & $\begin{array}{l}\text { Bakeshlou et al. [4], Guo et al. [25], Gupta and Barua [24], Iirajpour et al. [32], } \\
\text { Javad et al. [34], Kannan et al. [35], Lee et al. [41] }\end{array}$ \\
\hline Social responsibility & $\begin{array}{l}\text { Interest and rights of employees } \\
\text { Occupational health and safety } \\
\text { Legal compliance }\end{array}$ & $\begin{array}{l}\text { Amindoust et al. [3], Chiou et al. [15], Kannan et al. [36], Kuo et al. [40], Liu } \\
\text { et al. [42], Luthra et al. [44], Memari et al. [45], Orji and Wei [48], Ram- } \\
\text { akrishnan and Chakraborty [52], Roy et al. [53], Tavana et al. [61], Yucesan } \\
\text { et al. [66] }\end{array}$ \\
\hline Environmental competency & $\begin{array}{l}\text { Clean technology } \\
\text { Clean design } \\
\text { Low energy } \\
\text { Pollution reduction }\end{array}$ & $\begin{array}{l}\text { Büyüközkan [9], Chiou et al. [15], Guo et al. [25], Gupta and Barua [24], Javad } \\
\text { et al. [34], Kannan et al. [35], Phochanikorn and Tan [49], Yu and Hou [65] }\end{array}$ \\
\hline Green product & $\begin{array}{l}\text { Green packaging } \\
\text { Recycle } \\
\text { Disposal }\end{array}$ & $\begin{array}{l}\text { Acar et al. [1], Ecer [17], Gurel et al. [26], Ramakrishnan and Chakraborty } \\
\text { [52], Zafar et al. [67] }\end{array}$ \\
\hline
\end{tabular}


shipping, inventory, inspection, and security [21]. In this research, the cost criterion was examined with sub-criteria of product price, transportation cost, quantity discount, and payment terms.

H1. Affordable cost level has a positive effect on GSS.

Quality refers to the ability of the product or service to meet or exceed buyers' expectations [38]. The aim of organizations is to satisfy their customers with low-cost and highquality products, taking changing demands into account [52]. For this reason, companies must design their processes to meet quality standards. In this study, quality criteria are sub-divided as quality assurance, quality-related certificates, low defect rate, and low rejection rate.

\section{H2. Quality level has a positive effect on GSS.}

Delivery refers to the delivery of the product at the desired time without any damage, and delivery performance is a very important concept in terms of gaining a competitive advantage in today's customer-oriented market environment [38]. Delivery capability is recognized as an organizational capability [69]. In addition, a strong information link between the customer and the company is needed to meet customers' delivery expectations. The sub-criteria of order fulfillment rate, on-time delivery, and delivery communication system are the main components of delivery capability.

\section{H3. Delivery capability has a positive effect on GSS.}

The concept of service includes services provided to customers regarding the product before, during the sale, and after completion of the purchase for any product. Service level is an increasingly important concept for companies due to increasing customer expectations. To meet the rapidly changing needs of customers, the level of service promised to the customer needs to be optimized [23]. A company needs to be sensitive to customer needs in a rapidly-changing decision environment and establish an effective service system to fulfill customer demands [31]. In the current study, service level was defined by the sub-criteria on guarantees, responsiveness, and after-sales service.

H4. Service level has a positive effect on GSS.

Technology is a concept that encourages new product or process development for customers and the firm's ability to provide improved products [41]. The fact that the technological level of the supplier can meet the demands of its customers is an important component of customer preference [29]. In addition, the supplier's $R \& D$ and new product design capabilities must be at a level that meets customer expectations and needs. Therefore, in the present study, technological development, R\&D capability, and new product design sub-criteria are components in the technology criteria.

H5. Technological level has a positive effect on GSS.

Today, since traditional SS methods no longer meet the needs of businesses, it is necessary to include social dimensions in SS [48]. Customer and stakeholder concerns about corporate social responsibility have led many companies to implement socially responsible SC programs [40]. Supplier companies' focus on working relationships and the interests of their employees, providing productive programs to protect the health and safety of their staff and avoiding illegal activities are important factors for customers. In the current study, the interests and rights of employees, occupational health and safety, and legal compliance sub-criteria define the concept of social responsibility.

H6. Social responsibility has a positive effect on GSS.

In assessing a supplier's green SC compliance, the supplier's ability to protect the environment and achieve sustainable development should be considered [49]. Supplier companies should make choices that maximize their environmental competence in product design and the technology they use. A company with green competence has the ability to change processes and products to decrease the negative effect on natural resources [29]. In this study, environmental competence is represented by the concepts of the use of clean technology, clean design, low energy use, and pollution reduction.

H7. Environmental competency has a positive effect on GSS.

Green product refers to the use of non-toxic materials and recycling composites to reduce pollution, and the adoption of environmentally friendly production principles from the beginning of production to the delivery of the product [67]. For example, supplier companies should prefer packaging types that dissolve and disappear quickly in nature without causing harm [26] and raw materials that do not require high energy consumption in the recycling process. A supplier that meets the green product criterion uses environmentally friendly packaging techniques, can convert a used product into a reusable product, and has the ability to dispose of harmful materials. In the current study, the green product criterion is represented by the sub-criteria of green packaging, recyclability, and disposal.

H8. Green production has a positive effect on GSS. 
Some sub-criteria in the proposed model overlap semantically. For example, clean technology, pollution reduction, and green packaging are related concepts. Clean technology is a combination of a skilled workforce, advanced technology, and cognitive expertise. In the current study, R\&D activities are characterized by trained human resources and green innovation. Pollution reduction sub-criteria emphasize reducing the volume of waste, which may be subject to regulations, effective control of dangerous substances, and limiting the use of harmful substances in production. The green packaging sub-criterion advocates the use of materials in product packaging that can be disposed of without complex processing and less carbon composite in the packaging process.

\section{Application}

In the application part of this study, initially, the factors having desirable effects on a company's GSS are determined. Consequently, studies in the literature were meticulously examined to identify those aiming to activate GSS processes using MCDM techniques. For the current study, criteria recommended in relevant research and accepted as having an impact on SS were sought, and criteria applied in the SS process of a company operating in the textile sector were tested. In the next stage, the weights of the criteria were determined using SEM. Then, using the fuzzy ARAS technique, potentially suitable suppliers were identified.

\subsection{Determination of Criterion Weights}

A questionnaire consisting of two parts was developed for this study. In the first part, participants were asked about their gender, age, education level, work experience, and the department in which they work (Table 2). In the second part, sub-criteria obtained from the literature review were used. Participants were asked 30 questions evaluated on a fivepoint Likert-type scale.

A purposive sampling technique was used in sample selection. In determining the participants, being in the position of decision maker in SS was paramount. The prepared questionnaire was sent to senior and middle-level managers, purchasing, sales and marketing, and logistics department employees.

The implementation phase took place between February and July 2021, and the questionnaires were returned via e-mail to ensure reliability and prompt data collection. A total of 350 participants were recruited, and after removing incomplete and incorrectly filled data, 254 valid questionnaires remained for analysis. The collected data were analyzed with SEM in SPSS AMOS 22 software, and the
Table 2 Demographic information

\begin{tabular}{|c|c|c|}
\hline Classification & Frequency & Percentage $(\%)$ \\
\hline \multicolumn{3}{|l|}{ Gender } \\
\hline Female & 108 & 0.425 \\
\hline Male & 146 & 0.575 \\
\hline \multicolumn{3}{|l|}{ Age } \\
\hline $20-30$ & 78 & 0.307 \\
\hline $31-40$ & 59 & 0.232 \\
\hline $41-50$ & 42 & 0.165 \\
\hline $51-60$ & 47 & 0.185 \\
\hline $60+$ & 28 & 0.11 \\
\hline \multicolumn{3}{|l|}{ Education } \\
\hline High School & 39 & 0.154 \\
\hline University & 144 & 0.567 \\
\hline Master's and PhD & 71 & 0.28 \\
\hline \multicolumn{3}{|l|}{ Experience (year) } \\
\hline $0-1$ & 72 & 0.283 \\
\hline $2-5$ & 56 & 0.22 \\
\hline $5-10$ & 45 & 0.177 \\
\hline $10+$ & 81 & 0.319 \\
\hline \multicolumn{3}{|l|}{ Department } \\
\hline Senior executive & 29 & 0.114 \\
\hline Mid-level manager & 47 & 0.185 \\
\hline Purchasing & 82 & 0.323 \\
\hline Sales and marketing & 59 & 0.232 \\
\hline Logistic & 37 & 0.146 \\
\hline Total & 254 & 100 \\
\hline
\end{tabular}

proposed model was estimated using maximum likelihood estimation.

When evaluating the data, a two-phase process was adopted in which the measurement model is evaluated first and then the structural model. During this process, no revisions were made to the model. The measurement model was analyzed through confirmatory factor analysis (CFA), and the reliability of all items was examined from the factor loads perspective. Since factor loads of all items in the model were above the 0.5 value suggested in the literature [27], no item was excluded from the model (Table 3 ).

The measurement model was examined in terms of convergent and discriminant validity through CFA. Convergent validity refers to whether the constructs are highly related to their items. In the literature, it is recommended that the composite reliability (CR) value be greater than 0.6 and the average variance extracted (AVE) value be greater than 0.5 for constructs [14]. In addition, a construct with a Cronbach's alpha value above 0.7 is considered to have high internal reliability (Hinton et al. 2004). When the measurement model results were examined, it was observed that the Cronbach's alpha, CR, and AVE values of all constructs 
Table 3 Measurement model

\begin{tabular}{|c|c|c|c|c|c|}
\hline Construct & Item & Factor loading & Cronbach's alpha & $\mathrm{CR}$ & AVE \\
\hline \multirow[t]{4}{*}{ Cost } & 1 & 0.868 & \multirow[t]{4}{*}{0.924} & \multirow[t]{4}{*}{0.927} & \multirow[t]{4}{*}{0.761} \\
\hline & 2 & 0.882 & & & \\
\hline & 3 & 0.885 & & & \\
\hline & 4 & 0.855 & & & \\
\hline \multirow[t]{4}{*}{ Quality } & 1 & 0.848 & \multirow[t]{4}{*}{0.923} & \multirow[t]{4}{*}{0.925} & \multirow[t]{4}{*}{0.754} \\
\hline & 2 & 0.834 & & & \\
\hline & 3 & 0.918 & & & \\
\hline & 4 & 0.871 & & & \\
\hline \multirow[t]{3}{*}{ Delivery } & 1 & 0.850 & \multirow[t]{3}{*}{0.898} & \multirow[t]{3}{*}{0.9} & \multirow[t]{3}{*}{0.751} \\
\hline & 2 & 0.842 & & & \\
\hline & 3 & 0.906 & & & \\
\hline \multirow[t]{3}{*}{ Service } & 1 & 0.842 & \multirow[t]{3}{*}{0.906} & \multirow[t]{3}{*}{0.908} & \multirow[t]{3}{*}{0.766} \\
\hline & 2 & 0.9 & & & \\
\hline & 3 & 0.883 & & & \\
\hline \multirow[t]{3}{*}{ Technology } & 1 & 0.896 & \multirow[t]{3}{*}{0.901} & \multirow[t]{3}{*}{0.903} & \multirow[t]{3}{*}{0.757} \\
\hline & 2 & 0.867 & & & \\
\hline & 3 & 0.847 & & & \\
\hline \multirow[t]{3}{*}{ Social responsibility } & 1 & 0.89 & \multirow[t]{3}{*}{0.930} & \multirow[t]{3}{*}{0.930} & \multirow[t]{3}{*}{0.817} \\
\hline & 2 & 0.947 & & & \\
\hline & 3 & 0.873 & & & \\
\hline \multirow[t]{4}{*}{ Environmental competency } & 1 & 0.907 & \multirow[t]{4}{*}{0.945} & \multirow[t]{4}{*}{0.946} & \multirow[t]{4}{*}{0.813} \\
\hline & 2 & 0.863 & & & \\
\hline & 3 & 0.926 & & & \\
\hline & 4 & 0.909 & & & \\
\hline \multirow[t]{3}{*}{ Green product } & 1 & 0.848 & \multirow[t]{3}{*}{0.9} & \multirow[t]{3}{*}{0.903} & 0.756 \\
\hline & 2 & 0.899 & & & \\
\hline & 3 & 0.861 & & & \\
\hline GSS & 1 & 0.95 & 0.96 & 0.96 & 0.889 \\
\hline & 2 & 0.952 & & & \\
\hline & 3 & 0.927 & & & \\
\hline
\end{tabular}

were above the values considered acceptable in the literature (Table 3).

Discriminant validity occurs when the square root of the AVE values of the variables is greater than the correlations between the variables [14]. Discriminant validity analyzes whether the variable is a reflection of other variables. In the measurement model, the square root of the AVE of all constructs was greater than the relationship between all other constructs (Table 4). This indicates that the model has discriminant validity.

In the next step, the structural model was analyzed. To validate the structural model, the results of the fit analysis were examined, and it was seen that the model had acceptable fit (Table 5).

The results of the hypotheses obtained from the analysis of the structural model are shown in Fig. 1. According to those results, it was determined that the concepts of cost, quality, service, social responsibility, and green product have a positive and significant effect on SS. However, a positive and significant relationship could not be observed between delivery, technology, and environmental competency factors and SS. Therefore, H1, H2, H4, H6, and $\mathrm{H} 8$ are accepted, while H3, $\mathrm{H} 5$, and $\mathrm{H} 7$ are rejected.

Considering the structural model, the relative weights of the criteria were obtained through Eq. (1). The expression " $x_{j}$ " is the factor loading of the " $j$ " criterion. The expression " $y_{j}$ " refers to factor load sums of the criteria whose positive effect on SS was accepted. The weights of the criteria show the importance of the relevant criteria for the company in choosing a supplier (Table 6).

$A_{j}=\frac{x_{j}}{\sum_{j=1}^{J} x_{j}}$ 
Table 4 Discriminant validity

\begin{tabular}{|c|c|c|c|c|c|c|c|c|c|}
\hline Constructs & Cost & Quality & Delivery & Service & Technology & $\begin{array}{l}\text { Social } \\
\text { responsibil- } \\
\text { ity }\end{array}$ & $\begin{array}{l}\text { Environmental } \\
\text { competency }\end{array}$ & Green product & GSS \\
\hline Cost & 0.872 & - & - & - & - & - & - & - & - \\
\hline Quality & 0.189 & 0.868 & - & - & - & - & - & - & - \\
\hline Delivery & 0.405 & 0.543 & 0.867 & - & - & - & - & - & - \\
\hline Service & 0.245 & 0.411 & 0.695 & 0.875 & - & - & - & - & - \\
\hline Technology & 0.222 & 0.452 & 0.783 & 0.606 & 0.87 & - & - & - & - \\
\hline Social responsibility & 0.031 & 0.258 & 0.527 & 0.44 & 0.592 & 0.904 & - & - & - \\
\hline Environmental competency & 0.129 & 0.331 & 0.577 & 0.491 & 0.665 & 0.631 & 0.902 & - & - \\
\hline Green product & 0.081 & 0.209 & 0.497 & 0.374 & 0.539 & 0.472 & 0.604 & 0.869 & - \\
\hline GSS & 0.082 & 0.178 & 0.134 & 0.044 & 0.240 & 0.013 & 0.137 & 0.042 & 0.943 \\
\hline
\end{tabular}

Diagonal values are square root of AVEs of factors (in bold)

Table 5 Model fit results

\begin{tabular}{llll}
\hline Indices & Model & Acceptable fit & Reference \\
\hline$\chi^{2} / \mathrm{df}$ & 1.824 & $0<\mathrm{x} \leq 3$ & Schermelleh-Engel, Moosbrugger and Müller [56] \\
RMSEA & 0.057 & $0.05<\mathrm{x} \leq 0.08$ & \\
SRMR & 0.0516 & $0.05<\mathrm{x} \leq 0.1$ & \\
NFI & 0.911 & $0.9 \leq \mathrm{x}<0.95$ & \\
CFI & 0.957 & $0.95 \leq \mathrm{x}<0.97$ & \\
\hline
\end{tabular}

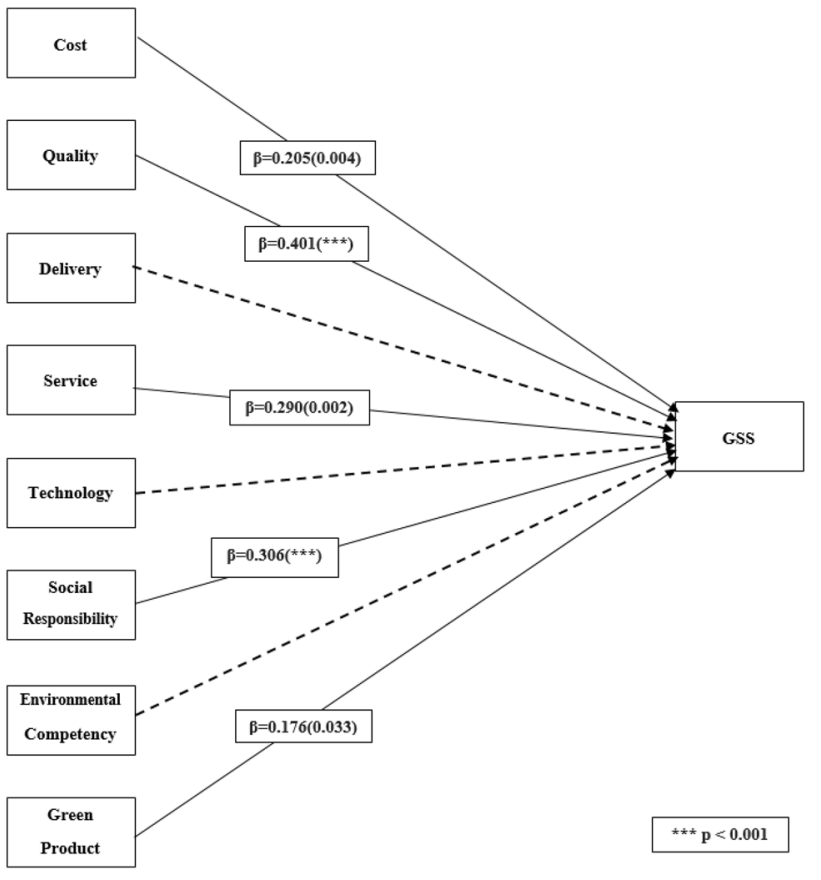

Fig. 1 Results of hypothesis testing

\subsection{Evaluation of Supplier Alternatives}

In this part of the study, strategies for evaluating of GSS alternatives were examined. The proposed approach was
Table 6 Weights of criteria

\begin{tabular}{ll}
\hline Criteria & Relative weight \\
\hline Cost & 0.149 \\
Quality & 0.291 \\
Service & 0.21 \\
Social responsibility & 0.222 \\
Green product & 0.128 \\
\hline
\end{tabular}

tested in the SS of a company operating in the textile industry. To evaluate alternatives, a committee was formed consisting of five decision makers working in a textile company with an effective say in SS, each with more than 10 years of experience in the sector-the general manager, sales and marketing manager, purchasing manager, purchasing specialist, and logistics operation specialist. The decision makers evaluated six supplier alternatives $\left(A_{n}\right)$ by considering five criteria that have positive and significant effects on SS. The weights of the mentioned criteria were obtained from the analysis of the structural model.

The ARAS method is an MCDM method developed by Turksis and Zavadskas (2010) that ranks decision alternatives according to utility function value, taking various criteria into account. The method compares the performance of alternatives over their proportional similarities to the performance of the optimum alternative [16]. The difference between the ARAS method and other MCDM 
techniques is that it compares the utility function values of the alternatives in the decision problem with the utility function value of the optimal alternative added to the decision problem by the expert. Thus, the performances of the decision alternatives are determined, and the proportional similarity of each decision alternative with respect to the ideal alternative is calculated. The steps followed in the implementation of the study are given below [37].

Step 1. Decision makers evaluate the alternatives through the linguistic variables given in Table 7 [55], and these evaluations are converted into triangular fuzzy numbers (TFS).

Step 2. As a result of the evaluations made by the experts, a fuzzy decision matrix (FDM) is formed, as in Eq. (2). In the FDM, there is a row consisting of the optimal values of each criterion. In the matrix given in Eq. (2), " $m$ " indicates the number of alternatives, and " $n$ " represents the number of criteria. The ratings of TFS are defined in the format " $x_{i j}=\left(a_{i j}, b_{i j} c_{i j}\right)$. In this expression, $x$ represents the fuzzy performance of the alternative $i$ according to the $j$ criterion. The fuzzy rating is defined in Eq. (3). However, " $x_{0 j}$ " indicates the optimal value of the $j$ criterion. The optimal value is calculated using Eq. (4) for benefit-based criteria and Eq. (5) for cost-based criteria.

$\tilde{X}=\left[\begin{array}{cccc}\tilde{x}_{01} & \tilde{x}_{02} & \cdots & \tilde{x}_{0 n} \\ \tilde{x}_{11} & \tilde{x}_{12} & \cdots & \tilde{x}_{1 n} \\ \vdots & \vdots & \cdots & \vdots \\ \tilde{x}_{m 1} & \tilde{x}_{m 2} & \cdots & \tilde{x}_{m n}\end{array}\right]$

$\tilde{x}_{i j}=\left(a_{i j}, b_{i j} c_{i j}\right)$

$\tilde{x}_{0 j}=\max _{i} \tilde{x}_{i j}$

$\tilde{x}_{0 j}=\min _{i} \tilde{x}_{i j}$

Step 3. A normalized FDM is created by applying the normalization process. While applying the normalization process, Eq. (6) is used for benefit-based criteria, and Eq. (7) is used for cost-based criteria.

Table 7 Linguistic variables for evaluating alternatives

\begin{tabular}{ll}
\hline Linguistic variable & TFS \\
\hline Very unsuccessful & $(0,0,1)$ \\
Unsuccessful & $(0,1,3)$ \\
Partially unsuccessful & $(1,3,5)$ \\
Intermediate & $(3,5,7)$ \\
Partially successful & $(5,7,9)$ \\
Successful & $(7,9,10)$ \\
Very successful & $(9,10,10)$ \\
\hline
\end{tabular}

$$
\begin{gathered}
\tilde{\bar{x}}_{i j}=\frac{\tilde{x}_{i j}}{\sum_{i=0}^{m} \tilde{x}_{i j}} \\
\tilde{\bar{x}}_{i j}=\frac{1 / \tilde{x}_{i j}}{\sum_{i=0}^{m} \tilde{x}_{i j}}
\end{gathered}
$$

Step 4. By multiplying the elements of the normalized FDM with the criterion weights $\left(w_{j}\right)$ the weighted normalized FDM is calculated by means of Eq. (8).

$\tilde{\hat{x}}_{i j}=\widetilde{\bar{x}}_{i j} w_{j}$

Step 5 . The fuzzy optimality function value $\left(\tilde{S}_{i}\right)$ for each alternative is calculated using Eq. (9). Then, using the centroid method given in Eq. (10), the fuzzy values are clarified and the optimality function value $\left(S_{i}\right)$ is obtained.

$\tilde{S}_{i}=\sum_{j=1}^{n} \tilde{\bar{x}}_{i j}$

$S_{i}=\frac{1}{3}\left(\tilde{S}_{i l}+\tilde{S}_{i m}+\tilde{S}_{i u}\right)$

Step 6. In the last step of the method, the degree of utility $\left(K_{i}\right)$ is calculated and final ranking is obtained. The degree of utility is found by proportioning the optimality function $\left(S_{i}\right)$ of an alternative to the ideal degree of performance $\left(S_{0}\right)$. The degree of utility is calculated by Eq. (11). The relative efficiency of the alternatives is determined using the $K i$ ratios. Decision alternatives are evaluated by ordering the calculated values from largest to smallest.

$K_{i}=\frac{S_{i}}{S_{0}}$

As a result of the evaluations made by the experts in Table 7, an FDM was created (Table 8). The $\tilde{x}_{o j}$ determined using Eq. (3) are placed in the FDM. Then, the normalization process is applied by means of Eq. (6), and the normalized FDM given in Table 9 is obtained. The criteria weights obtained in Table 6 and the elements of the normalized FDM are multiplied using Eq. (8). Thus, the weighted normalized FDM presented in Table 10 is calculated. Then, $\tilde{S}_{i}$ values are calculated using Eq. (9), and $S_{i}$ values are calculated using Eq. (10). Finally, the $K_{i}$ values of all alternatives are obtained by means of Eq. (11), and final ranking of the alternatives is reached (Table 11).

According to the results of the application using the fuzzy ARAS method for the GSS of a firm operating in the textile sector, final ranking of the suppliers is given in Table 11 . According to the $K_{i}$ values, the suppliers are ranked as $A_{1}$ $-A_{4}-A_{6}-A_{2}-A_{5}-A_{3}$. According to this order, $A_{1}$ represents the best alternative, and $A_{3}$ is the worst alternative. 
Table 8 FDM

\begin{tabular}{llllll}
\hline- & Cost & Quality & Service & Social responsibility & Green product \\
\hline$A_{1}$ & $(6.119,8.139,9.587)$ & $(5.348,7.361,9.192)$ & $(4.514,6.544,8.559)$ & $(3.323,5.348,7.361)$ & $(3.323,5.348,7.361)$ \\
$A_{2}$ & $(1.246,3.323,5.348)$ & $(3.323,5.348,7.361)$ & $(4.076,6.119,8.139)$ & $(1.552,3.680,5.720)$ & $(1.246,3.323,5.348)$ \\
$A_{3}$ & $(1.246,3.323,5.348)$ & $(1.246,3.323,5.348)$ & $(1.552,3.680,5.720)$ & $(1.246,3.323,5.348)$ & $(1.246,3.323,5.348)$ \\
$A_{4}$ & $(3.936,6.015,7.905)$ & $(1.246,3.323,5.348)$ & $(7.114,8.670,9.587)$ & $(6.544,8.559,9.791)$ & $(6.544,8.559,9.791)$ \\
$A_{5}$ & $(4.514,6.544,8.559)$ & $(1.246,3.323,5.348)$ & $(1.552,3.680,5.720)$ & $(3.323,5.348,7.361)$ & $(2.408,4.514,6.544)$ \\
$A_{6}$ & $(3.323,5.348,7.361)$ & $(4.514,6.544,8.559)$ & $(5.720,7.740,9.387)$ & $(2.408,4.514,6.544)$ & $(3.323,5.348,7.361)$ \\
$\tilde{x}_{o j}$ & $(6.119,8.139,9.587)$ & $(5.348,7.361,9.192)$ & $(7.114,8.670,9.587)$ & $(6.544,8.559,9.791)$ & $(6.544,8.559,9.791)$ \\
\hline
\end{tabular}

Table 9 Normalized FDM

\begin{tabular}{llllll}
\hline- & Cost & Quality & Service & Social responsibility & Green product \\
\hline$A_{1}$ & $(0.231,0.199,0.179)$ & $(0.240,0.201,0.183)$ & $(0.143,0.145,0.151)$ & $(0.133,0.136,0.142)$ & $(0.135,0.137,0.143)$ \\
$A_{2}$ & $(0.047,0.081,0.1)$ & $(0.149,0.146,0.146)$ & $(0.129,0.136,0.144)$ & $(0.062,0.094,0.11)$ & $(0.051,0.085,0.104)$ \\
$A_{3}$ & $(0.047,0.081,0.1)$ & $(0.056,0.091,0.106)$ & $(0.049,0.082,0.101)$ & $(0.05,0.084,0.103)$ & $(0.051,0.085,0.104)$ \\
$A_{4}$ & $(0.149,0.147,0.147)$ & $(0.056,0.091,0.106)$ & $(0.225,0.192,0.169)$ & $(0.262,0.218,0.189)$ & $(0.266,0.22,0.19)$ \\
$A_{5}$ & $(0.17,0.16,0.159)$ & $(0.056,0.091,0.106)$ & $(0.049,0.082,0.101)$ & $(0.133,0.136,0.142)$ & $(0.098,0.116,0.127)$ \\
$A_{6}$ & $(0.125,0.131,0.137)$ & $(0.203,0.179,0.170)$ & $(0.181,0.172,0.166)$ & $(0.097,0.115,0.126)$ & $(0.135,0.137,0.143)$ \\
$\tilde{x}_{o j}$ & $(0.231,0.199,0.179)$ & $(0.240,0.201,0.183)$ & $(0.225,0.192,0.169)$ & $(0.262,0.218,0.189)$ & $(0.266,0.22,0.19)$ \\
\hline
\end{tabular}

Table 10 Weighted normalized FDM

\begin{tabular}{llllll}
\hline- & Cost & Quality & Service & Social responsibility & Green product \\
\hline$A_{1}$ & $(0.034,0.03,0.027)$ & $(0.07,0.059,0.053)$ & $(0.03,0.03,0.032)$ & $(0.03,0.03,0.031)$ & $(0.017,0.018,0.018)$ \\
$A_{2}$ & $(0.007,0.012,0.015)$ & $(0.043,0.043,0.043)$ & $(0.027,0.028,0.03)$ & $(0.014,0.021,0.024)$ & $(0.006,0.011,0.013)$ \\
$A_{3}$ & $(0.007,0.012,0.015)$ & $(0.016,0.026,0.031)$ & $(0.01,0.017,0.021)$ & $(0.011,0.019,0.023)$ & $(0.006,0.011,0.013)$ \\
$A_{4}$ & $(0.022,0.022,0.022)$ & $(0.016,0.026,0.031)$ & $(0.047,0.04,0.036)$ & $(0.058,0.048,0.042)$ & $(0.034,0.028,0.024)$ \\
$A_{5}$ & $(0.025,0.024,0.024)$ & $(0.016,0.026,0.031)$ & $(0.01,0.017,0.021)$ & $(0.03,0.03,0.031)$ & $(0.013,0.015,0.016)$ \\
$A_{6}$ & $(0.019,0.02,0.02)$ & $(0.059,0.052,0.049)$ & $(0.038,0.036,0.035)$ & $(0.021,0.025,0.028)$ & $(0.017,0.018,0.018)$ \\
$\tilde{x}_{o j}$ & $(0.034,0.03,0.027)$ & $(0.07,0.059,0.053)$ & $(0.047,0.04,0.036)$ & $(0.058,0.048,0.042)$ & $(0.034,0.028,0.024)$ \\
\hline
\end{tabular}

Table 11 Final decision matrix

\begin{tabular}{lllll}
\hline- & $\tilde{S}_{i}$ & $S_{i}$ & $K_{i}$ & Ranking \\
\hline$A_{1}$ & $(0.181,0.166,0.161)$ & 0.17 & 0.807 & 1 \\
$A_{2}$ & $(0.098,0.115,0.125)$ & 0.113 & 0.536 & 4 \\
$A_{3}$ & $(0.051,0.085,0.103)$ & 0.08 & 0.38 & 6 \\
$A_{4}$ & $(0.178,0.165,0.155)$ & 0.166 & 0.79 & 2 \\
$A_{5}$ & $(0.094,0.112,0.124)$ & 0.11 & 0.524 & 5 \\
$A_{6}$ & $(0.154,0.151,0.151)$ & 0.152 & 0.723 & 3 \\
$\tilde{x}_{o j}$ & $(0.244,0.205,0.181)$ & 0.21 & 1 & - \\
\hline
\end{tabular}

\subsection{Sensitivity Analysis}

The stability of the model must be confirmed as well as the sensitivity of the results to changes in the priority sequence of certain criteria [60]. Sensitivity analysis examines the relationships between the inputs and outputs of the application (Chen and Khan 2010). It analyses how the output variation in the model can be allocated to different sources; the model depends on the information given to it [54]. Analysing MCDM problems with sensitivity analysis is essential for understanding the model's behaviour and limitations. Identifying the effect of small changes on the evaluation results in certain parameters contributes to reducing the uncertainty of the decision problem.

In the sensitivity analysis conducted in this study, criteria weight ranges were determined for all criteria in which alternative green suppliers' rankings did not change. In this process, while the weights of other criteria remained constant, the weight of a particular criterion was changed to determine the interval in which the alternative ordering did not change. The ranges in which ranking remains constant for all criteria are presented in Fig. 2. 


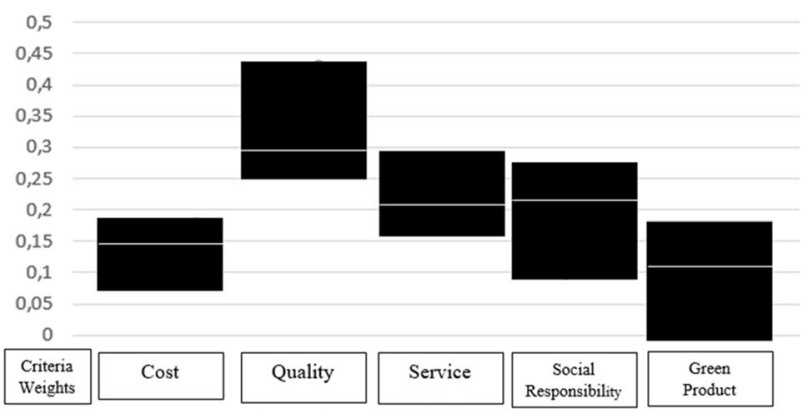

Fig. 2 Results of sensitivity analysis

The criteria are categorised as quality $(0.291)$, social responsibility $(0.222)$, service $(0.21)$, cost $(0.149)$, and green product $(0.128)$ according to their weights. The criterion most sensitive to a decrease in weight was quality. Supplier ranking changes when the weight of the quality criterion drops from 0.291 to below 0.261. In other words, a decrease of $10.3 \%$ in quality will alter the rankings. The second most sensitive criterion to reduction is service. When its weight falls below 0.166 , the ranking will change; that is, the weight of the service criterion must be reduced by $21 \%$ to effect a change. When the weight of the cost criterion falls below 0.082 - a change of $45 \%$ - the ranking will change. When the weight of the social responsibility criterion falls below 0.097 - a 56\% decrease-a different ranking occurs. Any decrease in the green product criterion fails to cause a change in the ranking.

The criterion most sensitive to an increase in weight is social responsibility. When its weight increases from 0.222 to above $0.265-\mathrm{a} 19.4 \%$ increase-supplier rankings change. A $19.5 \%$ increase to above 0.178 in the weight of the cost criterion will change the rankings, while the weight of the green product criterion must exceed 0.17 , an increase of $32.8 \%$, to push a change in ranking. When the service criterion is weighted above 0.285 - an increase of $35.7 \%$ rankings reflect a change, and in the quality criterion, the weight must exceed 0.43 , an increase of $47.8 \%$. In summary, the criterion most sensitive to a decline in weight is quality, and the criterion most sensitive to an increase is social responsibility.

\section{Conclusion}

Increasing concerns about environmental pollution and global warming, strict environmental regulations, and changing customer expectations have made manufacturers more sensitive to GSS. Activating the GSS process and determining the appropriate supplier directly affect SC performance. For this reason, businesses need a systematic and comprehensive evaluation system for GSS.
In this study, a hybrid approach, in which SEM and fuzzy ARAS techniques are used together, is proposed to carry out the GSS process effectively. In the first phase of the study, the literature on the subject was examined in detail, and eight main criteria and 27 sub-criteria were detected, taking classical, green, and social SS criteria into account. A questionnaire was administered to 254 participants who were actively involved in the SS process of their companies, and their responses were analyzed through SEM. When the structural model was examined, it was determined that cost, quality, service, social responsibility, and green product had positive and significant effects on GSS. In the second phase of the application, an expert committee comprised of five decision makers evaluated six alternatives, taking into account the five criteria that had positive effects on GSS. At this phase, the fuzzy ARAS was applied to select the most suitable supplier, and the potential suppliers were ranked.

The criteria that affect the choice of supplier are ranked in relation to quality $(0.291)$, social responsibility $(0.222)$, service $(0.21)$, cost $(0.149)$, and green product $(0.128)$. The results show that classical, environmental, and social criteria are effective in SS decision making. Although environmental criteria have undeniable importance in SS, a significant part of the total weight still consists of classical decision criteria. In addition, the fact that the social responsibility criterion has considerable weight is another noteworthy issue in the study. Thus, an integrated evaluation process will benefit businesses in making effective decisions. Researchers, company managers, and supplier companies working on the subject should consider the importance of green and social criteria as well as classical decision criteria.

Quality, one of the classical supplier evaluation criteria, was identified as the most effective factor in supplier evaluation in the current study. Quality, which is the ability of the supplied materials to meet the expectations of buyers [26], is seen as the most significant criterion in supplier evaluation. Therefore, suppliers who want to increase their effectiveness should design their processes to meet quality standards and offer quality assurance to their customers.

Social responsibility is of great importance in the evaluation of supplier performance, and its effects should be taken into account. Especially recently, customers' concerns about social responsibility have led many companies to implement social responsibility-oriented programs [40]. In the current study, it was determined that the concept of social responsibility is the second most effective factor in GSS. Therefore, supplier companies should implement social responsibility programs, focus on employee interests, comply with legal regulations, and focus on occupational health and safety.

Providing the promised level of service to customers and being sensitive to their demands are factors that make a supplier stand out. Today, due to increasing and rapidly changing customer expectations, the importance of service 
is constantly growing. Firms must be sensitive to customer expectations and meet their demands with the service systems they establish [31]. In the present study, the positive effect on SS of the level of service offered by companies has been affirmed. Companies gain competitive advantage with the warranty periods they apply to their products, the sensitivity they show to customer requests, and the after-sale services they offer.

The cost criterion is emphasized as the main concern of companies in traditional SS approaches [58]. Although its importance has declined over time due to changing customer needs, cost is still a factor affecting companies' SS decisions. In the analysis results, the effect of cost on SS was confirmed. The concept of cost can be expanded with many cost elements. Various economic opportunities provided by suppliers to their customers can affect customers' SS decisions.

Green product, which is defined as the adoption of environmentally friendly production methods at all stages, from the beginning of production to the delivery of the product, has become an important factor in SS, especially due to increasing environmental concerns. In the current study, it was determined that although green production is not as effective as the classical criteria in SS, it affects companies' SS decisions. Therefore, suppliers should use environmentally friendly packaging, prefer recyclable raw materials, and properly dispose of harmful solids and gases.

\section{Discussion}

In addition to developing a method by focusing clearly on the agreements and disagreements of many experts in the study and creating a decision-making model based on SEM and fuzzy ARAS techniques to solve SS problems appropriately and flexibly, the proposed approach can be applied to other decision problems in which a compromise solution is agreeable. This research is designed to support the GSS process and provide managers with a decision-making model for the factors they will consider in determining the green suppliers they will work with. The approach developed from a fuzzy logic perspective, in which criterion weights are taken into account through SEM, is presented and was tested in the GSS of a company operating in the textile industry.

With the scalable, generalizable, and practical approach proposed herein, potential loss of information and relative lack of transparency will be prevented. It will ensure that strategic decisions can be taken effectively and impartially, especially in those such as GSS, in which conflicts of opinion are intense and a compromise solution is sought. Criteria evaluation in the decision-making process was carried out using SEM analysis. Thus, information complexity and uncertainty, a common phenomenon in practical decision-making problems, have been overcome. The proposed method provides many benefits to researchers and managers in both theoretical and practical terms and offers an original structure to guide decision makers in the GSS process, thereby contributing to the creation of a sustainable SS process.

The study has some limitations, and the proposed approach needs to be expanded and applied in other research areas. Because an original approach was the aim of the research, triangular fuzzy sets, which have been used in the literature for many years, were preferred during the evaluation of alternatives. An original and up-to-date fuzzy logic approach may be preferred in future studies. In addition, the proposed method has not been compared with other methods available in the literature. Testing the model using different MCDM techniques and comparing the results will contribute further to the field. However, it did not examine the interactions between criteria. In future research, interrelationships between criteria may be considered.

The criteria in the model were determined through a literature review of studies conducted in different countries. For this reason, the model and the criteria used can be revised according to conditions specific to the sector and region. In addition, the list of criteria can be expanded by taking into account the sector and environmental policy of the enterprise performing the SS or the environmental regulations of the particular country. Finally, the approach tested in the context of GSS is expected to yield positive results in the context of other decision-making models. Testing the method in different decision problems is a research topic that will contribute to the literature.

\section{Declarations}

Conflict of interest The authors declare that they have no conflict of interest.

\section{References}

1. Acar, A. Z., Önden, İ., \& Gürel, Ö. (2016). Evaluation of the parameters of the green supplier selection decision in textile industry. Fibres \& Textiles in Eastern Europe, 8-14.

2. Alipour, M., Hafezi, R., Rani, P., Hafezi, M., \& Mardani, A. (2021). A new Pythagorean fuzzy-based decision-making method through entropy measure for fuel cell and hydrogen components supplier selection. Energy, 234, 121208.

3. Amindoust, A., Ahmed, S., Saghafinia, A., \& Bahreininejad, A. (2012). Sustainable supplier selection: A ranking model based on fuzzy inference system. Applied Soft Computing, 12(6), 1668-1677.

4. Bakeshlou, E. A., Khamseh, A. A., Asl, M. A. G., Sadeghi, J., \& Abbaszadeh, M. (2017). Evaluating a green supplier selection problem using a hybrid MODM algorithm. Journal of Intelligent Manufacturing, 28(4), 913-927. 
5. Banaeian, N., Mobli, H., Nielsen, I. E., \& Omid, M. (2015). Criteria definition and approaches in green supplier selectiona case study for raw material and packaging of food industry. Production \&amp; Manufacturing Research, 3(1), 149-168.

6. Banaeian, N., Nielsen, I. E., Mobli, H., \& Omid, M. (2014). Green supplier selection in edible oil production by a hybrid model using Delphi method and Green Data Envelopment Analysis (GDEA). Management and Production Engineering Review, 5(4), 3-8.

7. Beng, L. G., \& Omar, B. (2014). Integrating axiomatic design principles into sustainable product development. International Journal of Precision Engineering and Manufacturing-Green Technology, 1(2), 107-117.

8. Biswas, T. K., \& Das, M. C. (2020). Selection of the barriers of supply chain management in Indian manufacturing sectors due to COVID-19 impacts. Operational Research in Engineering Sciences: Theory and Applications, 3(3), 1-12.

9. Büyüközkan, G. (2012). An integrated fuzzy multi-criteria group decision-making approach for green supplier evaluation. International Journal of Production Research, 50(11), 2892-2909.

10. Cao, Q., Wu, J., \& Liang, C. (2015). An intuitionsitic fuzzy judgement matrix and TOPSIS integrated multi-criteria decision making method for green supplier selection. Journal of Intelligent \&amp; Fuzzy Systems, 28(1), 117-126.

11. Chatterjee, P., \& Stević, Ž. (2019). A two-phase fuzzy AHP-fuzzy TOPSIS model for supplier evaluation in manufacturing environment. Operational Research in Engineering Sciences: Theory and Applications, 2(1), 72-90.

12. Chattopadhyay, R., Chakraborty, S., \& Chakraborty, S. (2020). An integrated D-MARCOS method for supplier selection in an iron and steel industry. Decision Making: Applications in Management and Engineering, 3(2), 49-69.

13. Chen, Y., Yu, J., \& Khan, S. (2010). Spatial sensitivity analysis of multi-criteria weights in GIS-based land suitability evaluation. Environmental modelling \&amp; software, 25(12), 1582-1591.

14. Chin, W. W. (1998). The partial least squares approach to structural equation modelling. Modern Methods for Business Research, 295(2), 295-336.

15. Chiou, C. Y., Hsu, C. W., \& Hwang, W. Y. (2008). Comparative investigation on green supplier selection of the American, Japanese and Taiwanese electronics industry in China. In 2008 IEEE International Conference on Industrial Engineering and Engineering Management, 1909-1914.

16. Dadelo, S., Turskis, Z., Zavadskas, E. K., \& Dadeliene, R. (2012). Multiple criteria assessment of elite security personal on the basis of ARAS and expert methods. Economic Computation and Economic Cybernetics Studies and Research, 46(4), 65-88.

17. Ecer, F. (2020). Multi-criteria decision making for green supplier selection using interval type-2 fuzzy AHP: A case study of a home appliance manufacturer. Operational Research, 1-35.

18. Fallahpour, A., Olugu, E. U., Musa, S. N., Wong, K. Y., \& Noori, S. (2017). A decision support model for sustainable supplier selection in sustainable supply chain management. Computers and Industrial Engineering, 105, 391-410.

19. Fazlollahtabar, H., \& Kazemitash, N. (2021). Green supplier selection based on the information system performance evaluation using the integrated best-worst method. Facta Universitatis, Series.

20. Gbongli, K., Xu, Y., Amedjonekou, K. M., \& Kovács, L. (2020). Evaluation and classification of mobile financial services sustainability using structural equation modeling and multiple criteria decision-making methods. Sustainability, 12(4), 1288-1322.

21. Ghodsypour, S. H., \& O'Brien, C. (2001). The total cost of logistics in supplier selection, under conditions of multiple sourcing, multiple criteria and capacity constraint. International Journal of Production Economics, 73(1), 15-27.
22. Gotschol, A., De Giovanni, P., \& Vinzi, V. E. (2014). Is environmental management an economically sustainable business? Journal of Environmental Management, 144, 73-82.

23. Gunasekaran, A., Lai, K. H., \& Cheng, T. E. (2008). Responsive supply chain: A competitive strategy in a networked economy. Omega, 36(4), 549-564.

24. Gupta, H., \& Barua, M. K. (2017). Supplier selection among SMEs on the basis of their green innovation ability using BWM and fuzzy TOPSIS. Journal of Cleaner Production, 152, $242-258$.

25. Guo, Z., Liu, H., Zhang, D., \& Yang, J. (2017). Green supplier evaluation and selection in apparel manufacturing using a fuzzy multi-criteria decision-making approach. Sustainability, 9(4), $650,663$.

26. Gurel, O., Acar, A. Z., Onden, I., \& Gumus, I. (2015). Determinants of the green supplier selection. Procedia-Social and Behavioral Sciences, 181, 131-139.

27. Hair, J. F., Black, W. C., Babin, B. J., \& Anderson, R. E. (2010). Multivariate data analysis (7th ed.). Prentice Hall.

28. Handfield, R., Walton, S. V., Sroufe, R., \& Melnyk, S. A. (2002). Applying environmental criteria to supplier assessment: A study in the application of the Analytical Hierarchy Process. European Journal of Operational Research, 141(1), 70-87.

29. Hashemi, S. H., Karimi, A., \& Tavana, M. (2015). An integrated green supplier selection approach with analytic network process and improved Grey relational analysis. International Journal of Production Economics, 159, 178-191.

30. Hinton, P., McMurray, I., \& Brownlow, C. (2014). SPSS explained. Routledge.

31. Hsieh, T. Y., Lu, S. T., \& Tzeng, G. H. (2004). Fuzzy MCDM approach for planning and design tenders selection in public office buildings. International Journal of Project Management, $22(7), 573-584$.

32. Iirajpour, A., Hajimirza, M., Alavi, M. G., \& Kazemi, S. (2012). Identification and evaluation of the most effective factors in green supplier selection using DEMATEL method. Journal of Basic and Applied Scientific Research, 2(5), 4485-4493.

33. Jain, N., \& Singh, A. R. (2020). Sustainable supplier selection under must-be criteria through Fuzzy inference system. Journal of Cleaner Production, 248, 119275.

34. Javad, M. O. M., Darvishi, M., \& Javad, A. O. M. (2020). Green supplier selection for the steel industry using BWM and fuzzy TOPSIS: a case study of Khouzestan steel company. Sustainable Futures, 2, 100012.

35. Kannan, D., Khodaverdi, R., Olfat, L., Jafarian, A., \& Diabat, A. (2013). Integrated fuzzy multi criteria decision making method and multi-objective programming approach for supplier selection and order allocation in a green supply chain. Journal of Cleaner production, 47, 355-367.

36. Kannan, D., Mina, H., Nosrati-Abarghooee, S., \& Khosrojerdi, G. (2020). Sustainable circular supplier selection: A novel hybrid approach. Science of the Total Environment, 722, 137936.

37. Keršulienè, V., \& Turskis, Z. (2011). Integrated fuzzy multiple criteria decision making model for architect selection. Technological and Economic Development of Economy, 17(4), 645-666.

38. Kilic, H. S., \& Yalcin, A. S. (2020). Modified two-phase fuzzy goal programming integrated with IF-TOPSIS for green supplier selection. Applied Soft Computing, 93, 106371.

39. Kuo, T. C., \& Wang, C. J. (2019). Integrating robust design criteria and axiomatic design principles to support sustainable product development. International Journal of Precision Engineering and Manufacturing-Green Technology, 6(3), 549-557.

40. Kuo, R. J., Wang, Y. C., \& Tien, F. C. (2010). Integration of artificial neural network and MADA methods for green supplier selection. Journal of Cleaner Production, 18(12), 1161-1170. 
41. Lee, A. H., Kang, H. Y., Hsu, C. F., \& Hung, H. C. (2009). A green supplier selection model for high-tech industry. Expert Systems with Applications, 36(4), 7917-7927.

42. Liu, P., Gao, H., \& Ma, J. (2019). Novel green supplier selection method by combining quality function deployment with partitioned Bonferroni mean operator in interval type-2 fuzzy environment. Information Sciences, 490, 292-316.

43. Lu, Z., Sun, X., Wang, Y., \& Xu, C. (2019). Green supplier selection in straw biomass industry based on cloud model and possibility degree. Journal of Cleaner Production, 209, 995-1005.

44. Luthra, S., Govindan, K., Kannan, D., Mangla, S. K., \& Garg, C. P. (2017). An integrated framework for sustainable supplier selection and evaluation in supply chains. Journal of Cleaner Production, 140, 1686-1698.

45. Memari, A., Dargi, A., Jokar, M. R. A., Ahmad, R., \& Rahim, A. R. A. (2019). Sustainable supplier selection: A multi-criteria intuitionistic fuzzy TOPSIS method. Journal of Manufacturing Systems, 50, 9-24.

46. Meng, Q., Li, F. Y., Zhou, L. R., Li, J., Ji, Q. Q., \& Yang, X. (2015). A rapid life cycle assessment method based on green features in supporting conceptual design. International Journal of Precision Engineering and Manufacturing-Green Technology, 2(2), 189-196.

47. Mina, H., Mirabedini, S. N., Kian, H., \& Ghaderi, S. F. (2014). A new two stage integrated approach for green supplier selection. Applied Mathematics in Engineering, Management and Technology, 1(1), 1247-1126.

48. Orji, I. J., \& Wei, S. (2014). A decision support tool for sustainable supplier selection in manufacturing firms. Journal of Industrial Engineering and Management (JIEM), 7(5), 1293-1315.

49. Phochanikorn, P., \& Tan, C. (2019). An integrated multi-criteria decision-making model based on prospect theory for green supplier selection under uncertain environment: A case study of the Thailand palm oil products industry. Sustainability, 11(7), 1872-1894.

50. Punniyamoorty, M., Mathiyalagan, P., \& Lakshmi, G. (2012). A combined application of structural equation modeling (SEM) and analytic hierarchy process (AHP) in supplier selection. Benchmarking: An International Journal, 19(1), 70-92.

51. Punniyamoorthy, M., Mathiyalagan, P., \& Parthiban, P. (2011). A strategic model using structural equation modeling and fuzzy logic in supplier selection. Expert Systems with Applications, $38(1), 458-474$

52. Ramakrishnan, K. R., \& Chakraborty, S. (2020). A cloud topsis model for green supplier selection. Facta Universitatis, Series: Mechanical Engineering, 18(3), 375-397.

53. Roy, S. A., Ali, S. M., Kabir, G., Enayet, R., Suhi, S. A., Haque, T., \& Hasan, R. (2020). A framework for sustainable supplier selection with transportation criteria. International Journal of Sustainable Engineering, 13(2), 77-92.

54. Saltelli, A., Chan, K., \& Scott, M. (2000). Sensitivity Analysis. Probability and Statistics Series. John Wiley \& Sons.

55. Saremi, M., Mousavi, S. F., \& Sanayei, A. (2009). TQM consultant selection in SMEs with TOPSIS under fuzzy environment. Expert Systems with Applications, 36(2), 2742-2749.

56. Schermelleh-Engel, K., Moosbrugger, H., \& Müller, H. (2003). Evaluating the fit of structural equation models: Tests of significance and descriptive goodness-of-fit measures. Methods of Psychological Research Online, 8(2), 23-74.

57. Sharma, D. G., \& Rawani, A. M. (2016). Green supplier selection for Indian cement industry: AHP based approach. International Research Journal of Engineering and Technology, 3, 2368-2373.

58. Simpson, P. M., Siguaw, J. A., \& White, S. C. (2002). Measuring the performance of suppliers: An analysis of evaluation processes. Journal of Supply Chain Management, 38(4), 29-41.
59. Soubihia, D. F., Jabbour, C. J. C., \& de Sousa Jabbour, A. B. L. (2015). Green manufacturing: Relationship between adoption of green operational practices and green performance of Brazilian ISO 9001-certified firms. International Journal of Precision Engineering and Manufacturing-Green Technology, 2(1), 95-98.

60. Stević, Ž, Vasiljević, M., Puška, A., Tanackov, I., Junevičius, R., \& Vesković, S. (2019). Evaluation of suppliers under uncertainty: A multiphase approach based on fuzzy AHP and fuzzy EDAS. Transport, 34(1), 52-66.

61. Tavana, M., Yazdani, M., \& Di Caprio, D. (2017). An application of an integrated ANP-QFD framework for sustainable supplier selection. International Journal of Logistics Research and Applications, 20(3), 254-275.

62. Tian, Z. P., Zhang, H. Y., Wang, J. Q., \& Wang, T. L. (2018). Green supplier selection using improved TOPSIS and best-worst method under intuitionistic fuzzy environment. Informatica, 29(4), 773-800.

63. Wu, C., Lin, Y., \& Barnes, D. (2021). An integrated decisionmaking approach for sustainable supplier selection in the chemical industry. Expert Systems with Applications, 184, 115553.

64. Yazdani, M., Torkayesh, A. E., Stević, Ž., Chatterjee, P., Ahari, S. A., \& Hernandez, V. D. (2021). An Interval Valued Neutrosophic Decision-Making Structure for Sustainable Supplier Selection. Expert Systems with Applications, 115354.

65. Yu, Q., \& Hou, F. (2016). An approach for green supplier selection in the automobile manufacturing industry. Kybernetes, 45(4), 571-588.

66. Yucesan, M., Mete, S., Serin, F., Celik, E., \& Gul, M. (2019). An integrated best-worst and interval type-2 fuzzy TOPSIS methodology for green supplier selection. Mathematics, 7(2), 182-201.

67. Zafar, A., Zafar, M., Sarwar, A., Raza, H., \& Khan, M. T. (2018, August). A fuzzy AHP method for green supplier selection and evaluation. In International Conference on Management Science and Engineering Management, Springer, Cham, 1355-1366.

68. Zavadskas, E. K., \& Turskis, Z. (2010). A new additive ratio assessment (ARAS) method in multicriteria decision-making. Technological and Economic Development of Economy, 16(2), 159-172.

69. Zehir, C., \& Acar, A. Z. (2006). Organizational capabilities and its impacts on business performance. In The Proceedings of 2nd International Strategic Management Conference, 163(1), 163-172.

Publisher's Note Springer Nature remains neutral with regard to jurisdictional claims in published maps and institutional affiliations.

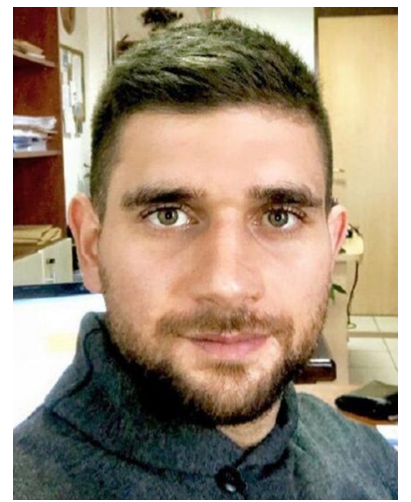

Rahmi Baki is an Assistant Professor Doctor in the Department of Management Information Systems at Aksaray University, Turkey. Dr. Baki has received the BSc degree in industrial engineering from Gazi University in 2011, MSc degree in industrial engineering from Gazi University in 2014 and $\mathrm{PhD}$ degree from Kırıkkale University Industrial Engineering Department in 2019. His academic interest areas are multi criteria decision making, fuzzy logic, structural equation modeling, supply chain

management and distance education. 